\title{
A Short Review on Various Types Transmission Tower Structure and Its Design
}

\author{
Swarup Sontakke $^{1}$, Dr. C. N. Sakhale ${ }^{2}$ \\ ${ }^{1,2,}$ Mechanical Engineering Department, Priyadarshini College of Engineering, Nagpur - India.
}

\begin{abstract}
This paper will be helpful for researchers and electrical utilities involved in design and condition of Various types Structure in transmission towers line.
\end{abstract}

Keywords- Transmission tower structure, Design condition and application, Selection of tower

\section{I- INTRODUCTION}

The transmission lines are connecting links between generating station to Distribution system. Since the rate of growth being greater in developments countries which are turns had led the increase in the number of tower lines \& tower was observer.

Transmission towers support the high-voltage conductors of overhead power lines, from the generating station switchyard right up to the source substations and satellite substations located near populated areas.

Their shape, height and sturdiness (mechanical strength) depend on the stresses to which they are exposed. Towers do not transmit electricity themselves unless lightning strikes the ground wire strung along the top of the structure. This cable is designed to protect conductors by allowing lightning discharges to reach the ground through the tower.

What is a Transmission Tower?

A transmission tower (also known as a power transmission tower, power tower, or electricity pylon) is a tall structure (usually a steel lattice tower) used to support an overhead power line. In electrical grids, they are used to carry high voltage transmission lines that transport bulk electric power from generating stations to electrical substations; utility poles are used to support lower-voltage sub-transmission and distribution lines that transport power from substations to electric customers.

Transmission towers have to carry the heavy transmission conductors at a sufficient safe height from the ground. In addition to that, all towers have to sustain all kinds of natural calamities. So transmission tower design is an important engineering job where civil, mechanical, and electrical engineering concepts are equally applicable. 


\section{International Journal of Innovations in Engineering and Science, www.ijies.net}

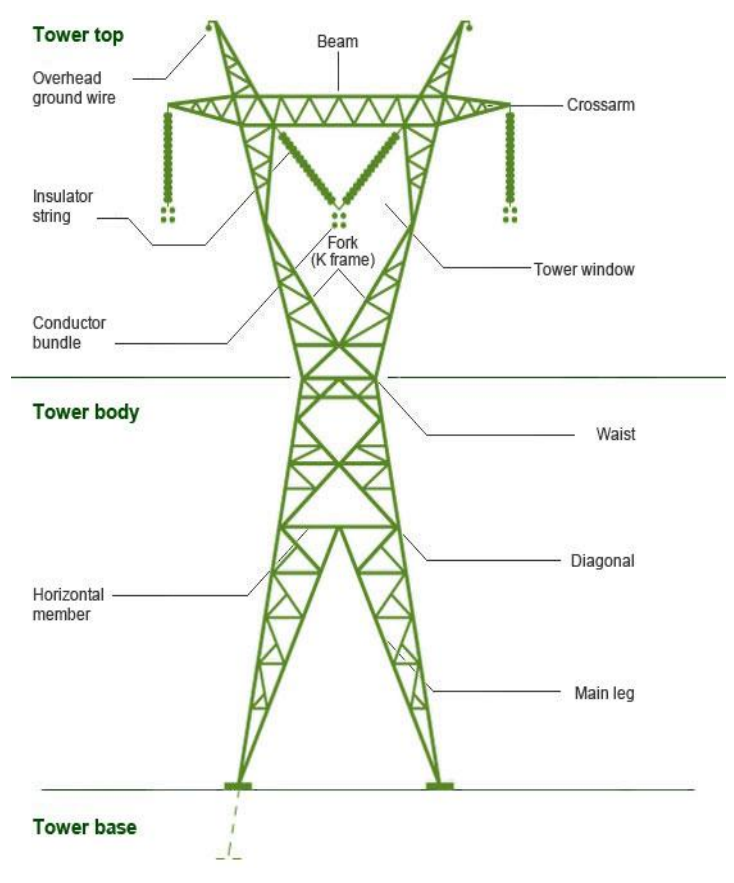

Fig 1-Parts of Transmission Tower

\section{II- TRANSMISSION TOWER DESIGN}

During design of transmission tower the following points to be considered in mind,

- The minimum ground clearance of the lowest conductor points above the ground level.

- The length of the insulator string.

- The minimum clearance to be maintained between conductors and between conductor and tower.

- The location of a ground wire with respect to outermost conductors.

- The midspan clearance required from considerations of the dynamic behaviour of the conductor and lightning protection of the power line.

To determine the actual transmission tower height by considering the above points, we have divided the total height of the tower into four parts:

- Minimum permissible ground clearance (H1)

- Maximum sag of the overhead conductor (H2)

- Vertical spacing between the top and bottom conductors (H3)

Vertical clearance between the ground wire and top conductor (H4)

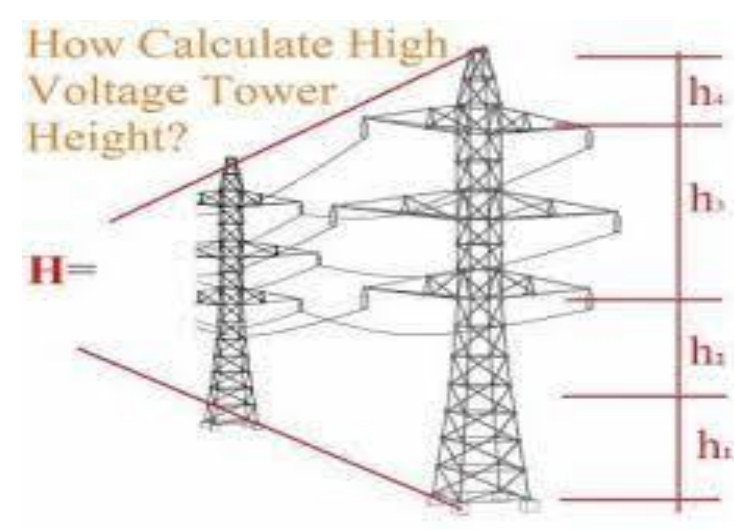

Fig 2-Height of the Tower

The higher the voltage of the transmission line, the higher the ground clearance and vertical spacing tends to be. i.e. high voltage towers will have a higher permissible ground clearance and larger vertical spacing between the top and bottom conductors.

\section{Selection of Transmission Tower}

1. Height of tower

2. Base width of tower

3. Cross arm length

4. Single circuit tower / double circuit tower

5. According KV current capacity

6. According to angle of deviation

7. According Soil, Wind Speed \& zone

8. Length of insulator assembly

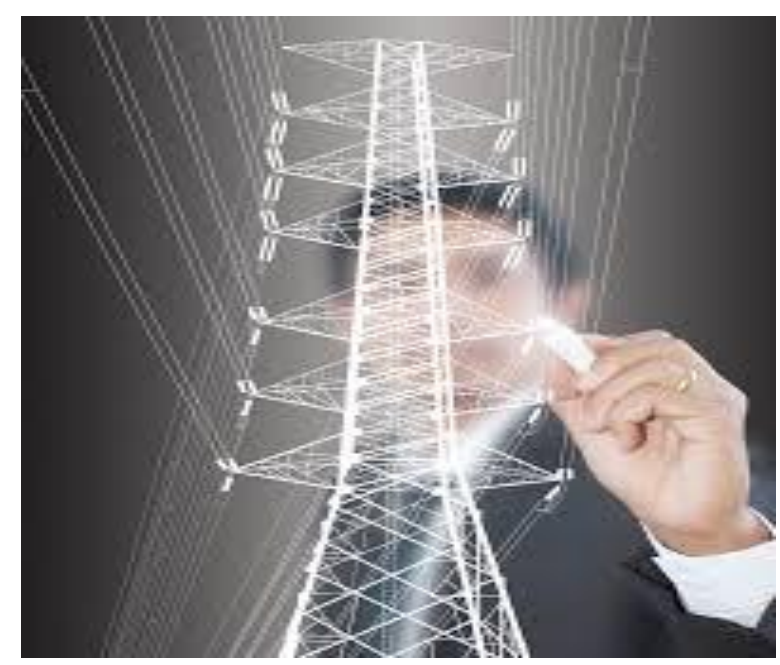

Fig 3-Design of Transmission Tower

9. Minimum clearance to be maintained between ground conductor \& between conductor \& tower

10. Location of ground wire / Wire with respective to the outermost conductor 


\section{International Journal of Innovations in Engineering and Science, www.ijies.net}

11. Mid-span clearance required from consideration of the dynamic behaviors of conductor \& lightning protection of the line

12. Minimum clearance of the lowest conductor of the ground level.

13. According to Power line, Railway line, National, District, Village Road crossing \& River

\section{III- TYPES OF ELECTRICAL TRANSMISSION TOWERS}

According to different considerations, there are different types of transmission towers. The transmission line goes as per available corridors. Due to the unavailability of the shortest distance straight corridor transmission line has to deviate from its straightway when obstruction comes. In the total length of a long transmission line, there may be several deviation points.

1. According to the angle of deviation, there are four types of transmission tower-

a) A - type tower - angle of deviation $0^{\circ}$ to $2^{\circ}$.

b) $\mathrm{B}$ - type tower - angle of deviation $2^{\circ}$ to $15^{\circ}$.

c) C - type tower - angle of deviation $15^{\circ}$ to $30^{\circ}$.

d) $\mathrm{D}$ - type tower - angle of deviation $30^{\circ}$ to $60^{\circ}$.

e) $\mathrm{E}$ - type tower - angle of deviation $60^{\circ}$ to $90^{\circ}$.

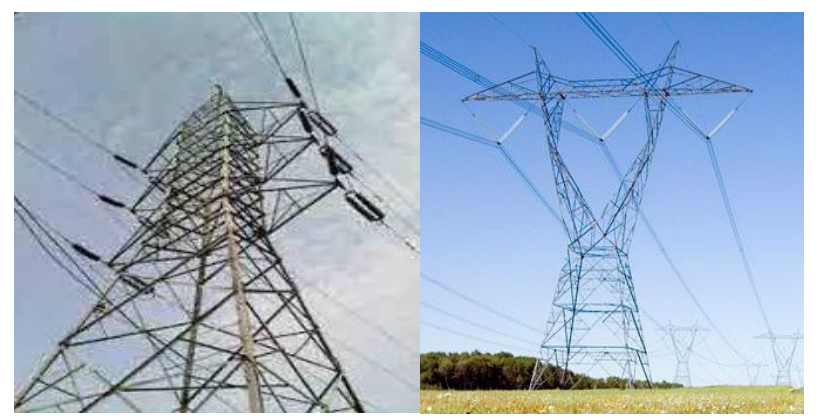

Fig 4-Tangent \& Suspension Tower (from $0^{\circ}$ to $60^{\circ}$ )

2. As per the force applied by the conductor on the cross arms, the transmission towers can be categorized in another way-

a) Tangent suspension tower and it is generally $\mathrm{A}-$ type tower.

b) Angle tower or tension tower or sometime it is called section tower. All B, C and D types of transmission towers come under this category.

c) Apart from the above-customized type of tower, the tower is designed to meet special usages listed below:

These are called special type tower

a) River crossing tower

b) Railway/ Highway crossing tower

c) Transposition tower
3. Based on numbers of circuits carried by a transmission tower, it can be classified as-

a) Single circuit tower

b) Double circuit tower

c) Multi circuit tower.

4. Based on Structure types by a transmission tower, it can be classified as-

a) Lattice Structure

b) Hybrid Structure

c) Tubular Pole Structure

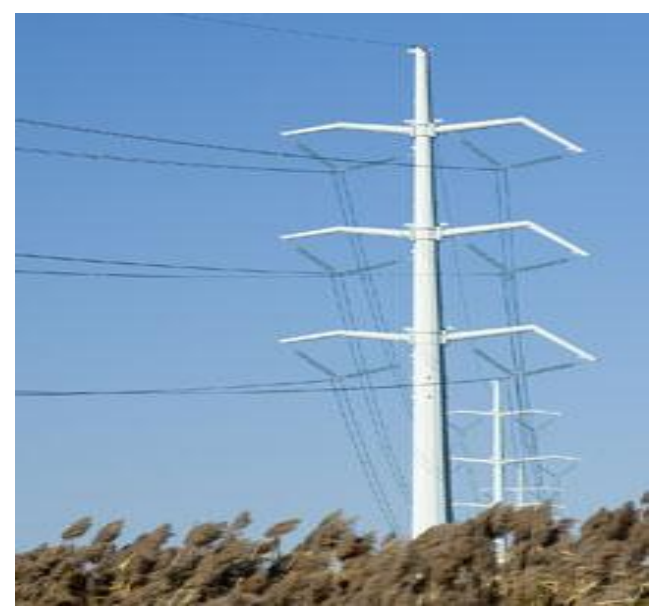

Fig 5-Tubular Pole Structure

5. Classification is forming the point of view of material used, it can be classified as-
a) Steel Structure
b) Wooden Material
c) RCC Pole

6. On the basis of current types of towers

a) HVAC transmission tower

b) HVDC transmission tower

c) Railway traction line tower

7. On the basis of current caring capacity in $\mathrm{kV}$
a) $11 \mathrm{kV}$,
b) $33 \mathrm{kV}$
c) $66 \mathrm{kV}$
d) $110 \mathrm{kV}$
e) $132 \mathrm{kV}$
f) $220 \mathrm{kV}$
g) $400 \mathrm{kV}$
h) $500 \mathrm{kV}$
i) $765 \mathrm{kV}$
j) $800 \mathrm{kV}$
k) $1200 \mathrm{kV}$ 


\section{International Journal of Innovations in Engineering and Science, www.ijies.net}

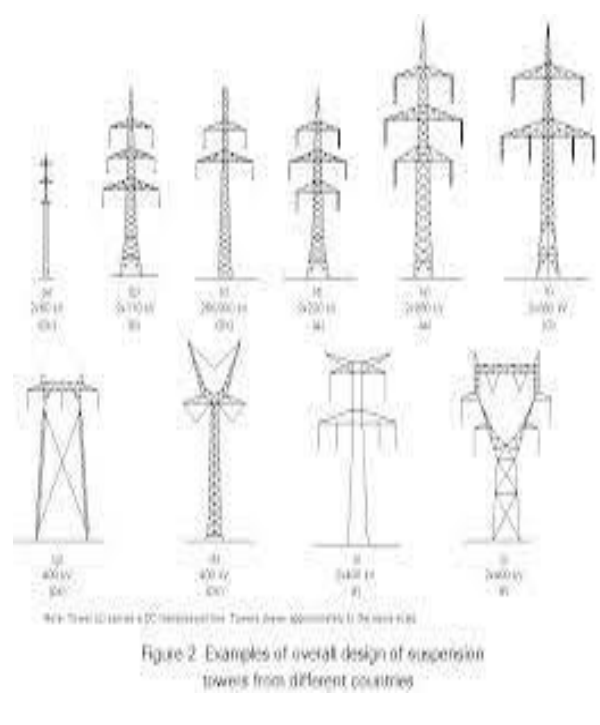

Fig 6- According to Current Capacity

\section{Structure Configuration and Material}

Structure cost usually accounts for 30 to $40 \%$ of the total cost of a transmission line. Therefore, selecting an optimum structure becomes an integral part of a costeffective transmission line design.

A structure study usually is performed to determine the most suitable structure configuration and

material based on cost, construction, and maintenance considerations and electric and magnetic field effects. Some key factors to consider when evaluating the structure configuration are:

- A horizontal phase configuration usually results in the lowest structure cost.

- If right-of-way costs are high, or the width of the right-of-way is restricted or the line closely parallels other lines, a vertical configuration may be lower in total cost.

- In addition to a wider right-of-way, horizontal configurations generally require more tree clearing than vertical configurations.

- Although vertical configurations are narrower than horizontal configurations, they are also taller, which may be objectionable from an aesthetic point of view.

Where electric and magnetic field strength is a concern, the phase configuration is considered as a means of reducing these fields. In general, vertical configurations will have lower field strengths at the edge of the right-of-way than horizontal configurations, and delta configurations will have the lowest single-circuit field strengths and a double-circuit with reverse or low-reactance phasing will have the lowest possible field strength. Selection of the structure type and material depends on the design loads. For a single circuit $230-\mathrm{kV}$ line, costs were estimated for single-pole and $\mathrm{H}$-frame structures in wood, steel, and concrete over a range of design span lengths. For this example, wood $\mathrm{H}$-frames were found to have the lowest installed cost, and a design span of $1000 \mathrm{ft}$ resulted in the lowest cost per mile. As design loads and other parameters change, the relative costs of the various structure types and materials change.

\section{IV- CONCLUSION}

The remotion of power required nonlinear analysis and the redesign of connection and replacement of some element of its types. According to use of tower, We have to select the proper types and structure of tower, be replaced with new connection full also replace where they have the failed.

Horizontal tie members will help form diaphragm at the top model height of the tower according to area and its uses. The various types transmission tower indicates that the under the certain wind speed, direction, Angle area, the tower will select, the tower will help to resist lateral force which will reduce the leg loads to acceptable level.

\section{REFERENCE}

[1] IS 802 Part 1 Sec 11995 Codeof practice for use of structural steel in overhead transmission line towers, Part 1

[2] C. Preeti 1) and K. Jagan Mohan (2013), “Analysis of Transmission Towers with Different Configurations" Jordan Journal of Civil Engineering, Volume 7, No. 4.

[3] Yoganantham.C Helen Santhi.M (2013), "Dynamic Analysis of Transmission Towers International Journal of Advanced Information Science and Technology (IJAIST)"'Vol.20, No.20.

[4] Umesh S. Salunkhe and Yuwaraj M. Ghugal (2013)," Analysis And Design Of Three Legged 400kV Double Circuit Steel Transmission Line Towers International Journal of Civil Engineering and Technology" Vol. 04, Issue 3.

[5] Srikanth L.and Neelima Satyam D (2014), "Dynamic Analysis Of Transmission Line Towers International Journal of Civil, Environmental, Structural, Construction and Architectural Engineering Vol:8, No:4.

[6] Dharmender Panth, IIT-BHU,Varanasi, U.P., India, Reasons For Failure Of Transmission Lines And Their Prevention Strategies, Volume-2, Issue-1, 
Vol. 6, No. 9, 2021, PP. 9- 13

International Journal of Innovations in Engineering and Science, www.ijies.net

Jan.-2014

[7] Siti Aisyah Kamarudin, Fathoni Usman, Intan Nor Zuliana Baharuddin " Review on analysis and design of lattice steel structure of overhead transmission tower" College of Graduate Studies, Universiti Tenaga Nasional, Kajang, Malaysia ,Institute of Energy Infrastructure, Universiti Tenaga Nasional, Kajang, Malaysia

[8] Vinay RB, Ranjith A, and Bharath A (2014). Optimization of transmission line towers : P-Delta analysis. International Journal of Innovative Research in Science, Engineering and Technology, 3(7): 14563-14569.

[9] Usman F and Megat Asyraf MIR (2011). Simulation of progressive collapse for transmission tower. In the 1st TNB ICT Technical Conference, College of Information Technology, Universiti Tenaga Nasional, Kajang, Malaysia.

[10] Rao NP, Knight GS, Mohan SJ, and Lakshmanan N (2012). Studies on failure of transmission line towers in testing. Engineering Structures, 35: 55-70.

[11] Rao NP and Kalyanaraman V (2001). Non-linear behaviour of lattice panel of angle towers. Journal of Constructional Steel Research, 57(12): 1337-1357.

[12] Preeti C and Mohan JK (2013). Analysis of transmission towers with different configurations. Jordan Journal of Civil Engineering, 7(4): 450-460.

[13] McClure G and Lapointe M (2003). Modeling the structural dynamic response of overheadtransmission lines. Computers and Structures, 81(8): 825-834. 